\title{
Staffing the Respiratory Care Department: New Considerations
}

The basic human-resources management tenets of attract, retain, and motivate the best practitioners remain at the core of management focus; however, time standards, volumes, staffing variables, and flexible budgets are concepts that have become increasingly important in managing respiratory care departments. Labor productivity is one of the most important priorities of any business, and labor is the largest expense for healthcare organizations. Labor typically represents more than $60 \%$ of a respiratory care department's total costs. ${ }^{1}$ The justification of resources and equitable work-load distribution require formal productivity reporting systems and established staffing strategies. Considering the month-to-month, day-to-day, and even hour-to-hour variability in work demand, and having systems in place that are sensitive to work-load fluctuations provides a data-driven approach to adjusting labor hours scheduled. Essential for successful respiratory departments is the development of systems and strategies that ensure adequate numbers of qualified personnel to meet the patients' needs at all times.

See the Original Study on Page 1785

In the provision of respiratory services, including enabling scientific research and the implementation of best practice, there is no greater dynamic than staffing. Managers are held accountable by administrators to do more with less and achieve challenging productivity targets while ensuring that resources are available to provide quality patient care. Having adequate numbers of qualified staff to do the right things right requires the ability to measure work demand. The American Association for Respiratory Care (AARC) Uniform Reporting Manual provides the mechanisms to measure such work. ${ }^{2}$ The methods used to measure work have typically been determined on a shiftto-shift basis. The AARC Uniform Reporting Manual helps identify staffing needs by accounting for the number of procedures due over a time period and identifying the amount of time required for each procedure. Staffing requirements are then calculated by multiplying the number of procedures by their specific time standards to determine total required hours needed. In addition, knowing the amount of work in any given nursing unit facilitates an approach to equitable distribution of work among the therapists on duty.
Refining work-load measurement and assignment programs remains a priority for respiratory care departments, as work-load issues are an important component of staff dissatisfaction. ${ }^{3}$ Even with staffing systems that determine shift demand using time standards, staff can become overwhelmed with work mid-shift and find themselves in situations in which treatment is delayed or patient prioritization policy must be applied. When the staffing system is limited to providing a "snapshot" view of the total work demand for the next shift, with little or no consideration for the times the treatments are due, staff may still have issues in getting all the work done during the shift. Many departments currently struggle with getting systems in place to quantify staffing needs. In this issue of RESPIRATORY CARE, Chatburn and colleagues ${ }^{4}$ report on a new system that goes beyond quantifying total work over the span of a shift. Their system quantifies clinical service demand on an hour-to-hour basis. They refer to the hour-to-hour demand as the "work rate." Their data demonstrate the extent to which treatment due times and unanticipated changes during the shift are cause for concern.

What Chatburn et $\mathrm{al}^{4}$ describe is not a new concept. For years practitioners and managers have observed duringshift work-load spikes because of treatment due times and unexpected urgent situations. Even with the best systems in place, work load can be unpredictable. Clinicians often simply do the best they can, eventually getting the work done. Many managers have responded by creating staffing models in which staff are redeployed mid-shift or float therapists are assigned to respond to the hourly variability in service demand. The single greatest challenge in developing a staffing system is the highly volatile nature of the demand for respiratory care services. When there is higher demand for services than the number of respiratory therapists scheduled, they prioritize their work, pick up the pace, and do the best they can. There are often not adequate resources to meet the peak demand periods. When departments staff for peaks, they run the risk of extra hours during the low-demand periods. Risks related to not having enough therapists include mistakes and staff "burnout" from severe challenge to coping skills and concentration ability. ${ }^{5}$

Chatburn et $\mathrm{al}^{4}$ quantify the problem and offer some new considerations. In a department such as pulmonary function testing we may see 10 patients a day, and of course we would not schedule them to all report at 9 AM. 
Patients are scheduled throughout the day to minimize patient waits and to give the technician adequate time to perform quality testing and to adjust to any unexpected changes in the testing schedule. The acute-care hospital environment is much more dynamic because patient care is not typically scheduled; so respiratory care scheduling must be dynamic, but useful systems can be put in place, as described by Chatburn et al. By staggering treatment due times and shift-start times, they responded to the hourly demand variability, minimized the risk of treatment delays, and better matched the demand for services with the clinician hours available to provide those services.

Another important factor discussed by Chatburn et al is unscheduled work (tasks not known at the start of shift), which at their institution they found to be as much as $40 \%$ of the work. The AARC Uniform Reporting Manual suggests a method to account for procedures not directly associated with patient treatment and other support activities. It is largely recognized that the practitioner's workday includes various support activities such as department meetings, in-services, rounds, stocking, reporting, paid breaks, and delays, which are factored into productivity determinations. But despite accounting for the support and nonallocated activities in a staffing system, there may be no consideration for unscheduled treatments that are assigned mid-shift or requested "as soon as possible" or "emergency," such as transports, bronchoscopy, rapid responses, and codes. By routinely measuring work load assigned and work load performed the manager can get a general assessment of the average number of unscheduled activities and incorporate them in the assignment of work.

There will probably be more focus on work rate as clinical information systems improve access to data on treatment due times versus and treatment performed times. The AARC has published a position statement regarding the acceptable times frames to provide treatment based on due times:

It is the position of the AARC that medical facilities need to establish written policies and procedures for the safe and timely administration of inhaled medications that are appropriate for the facility and approved by the medical staff. These policies may

\footnotetext{
The author has disclosed no conflicts of interest.

Correspondence: Richard M Ford RRT FAARC, Department of Respiratory Care, University of California San Diego, 200 W Arbor Drive, San Diego CA 92103-8771. E-mail: rmford@ucsd.edu.
}

DOI: $10.4187 /$ respcare. 01584

\begin{abstract}
differ from standard medication administration schedules and time frames, but must be implemented so that medications are administered as prescribedie, Q 1 hour, QID $4 \times$ per day, BID $2 \times$ per day, etc. If a facility establishes an alternative schedule for the safe and effective delivery of inhaled medications, the AARC recommends that the inhaled medication delivery schedule window not exceed $60 \mathrm{~min}$ before or after the scheduled medication delivery due time for medications prescribed at an interval greater than or equal to 4 hours. ${ }^{6}$
\end{abstract}

That AARC position statement provides a national standard for regulatory agency adoption in which there is greater awareness and accountability to get treatments performed when due and to have adequate staff to do so. The paper by Chatburn and colleagues ${ }^{4}$ on using work rate instead of work load, based on the hourly capture of relative value units provides new considerations for managers, regardless of whether they can actually measure work rate.

As both respiratory care and hospital clinical information systems are implemented, the measure of work rate may become a more practical metric that others can also apply. These represent important reasons why managers should consider work rate. Few departments may have the information systems needed to accurately capture work rate, but an understanding of the concepts provides managers with the opportunity to engage staff and create staffing and treatment programs that minimize the hourly variability in demand.

\author{
Richard M Ford RRT FAARC \\ Department of Respiratory Care \\ University of California San Diego \\ San Diego, California
}

\section{REFERENCES}

1. Thalman JJ, Ford RM. Labor and productivity measures. Respir Care Clin N Am 2004;10(2):211-221.

2. AARC uniform reporting manual. Irving, TX: American Association for Respiratory Care; 2004.

3. AARC human resource survey. Irving, TX: American Association for Respiratory Care; 2009.

4. Chatburn RL, Gole S, Schenk P, Hoisington E, Stoller JK. Respiratory care work assignment based on work rate instead of work load. Respir Care 2011;56(11):1785-1790.

5. Salyer JW. Managing the respiratory care department. Sudbury, MA: Jones and Bartlett; 2008:139-163.

6. American Association for Respiratory Care. Position statement: inhaled medication administration schedules: 2008. http://www.aarc. org/resources/position_statements/documents/InhaledMedication Schedule.pdf. Accessed September 7, 2011. 